\title{
Examination of The Impact of Smart Grid Technologies For Energy Saving Potential on Residential Buildings In India
}

\author{
Nisha.V, V.Vasudevan, A.Ramkumar
}

\begin{abstract}
India, a developing country has targeted 9\% growth rate, its yearly power generation has increased to $6.5 \%$ per year from 2011 to 2017. It is due to the fast urbanization and increase in building occupied area. However, India is experiencing energy scarcity nowadays. The power generation can't able to satisfy the demand to withstand its growth rate in future. Therefore, this study investigates some technologies for connecting residential buildings to the Smart Grid, to minimize electricity consumption. It can be achieved by optimizing consumer's devices through interface with Home Area Networks (HANs), Smart Grid-connected home machines diagnostics, and enhanced capability to aim and adopt energy efficiency agendas. These tactics create impacts on energy conservation that influencing the initial investment on new generation.
\end{abstract}

Keywords : Energy saving, India, Smart grid, Residential buildings

\section{INTRODUCTION}

$\mathrm{T}_{1}$ his Energy efficiency is a simplest, quickest, cleanest, and cheapest method to fulfill energy demands. India can able to save ₹ $3 \times 10^{5}$ crores yearly by extensively enhancing energy efficiency in buildings [1]. The government is responsible for fixing standards to hasten energy efficiency. It should form building codes and offer technical guidelines for connecting residential consumers to the smart girds. The implementation of smart grid technology ensures to offer profits to the consumers and the utility system to fulfill energy demands economically and eco-friendly.
Smart grid utilizes digital technology and communication to organize the operations of intelligent devices all over the power system comprising generation, transmission and distribution sectors (industries, commercial buildings, and homes). Moreover, it enhances the efficacies in the generation, transmission, distribution and end-use systems by enhancing system performance and increasing asset utilization. Hence, the smart grid actions have been developed in this decade consisting of demonstrations and technology deployments. The main customer parts such as housing, profitable and manufacturing; and the other features of the Smart Grid. The model consists of seven various rudiments that play vital part in a Smart Grid-connected home.

1. Home area network (HAN): It is a chief device for create interaction between the devices in a home.

2. Smart meter or Automated Metering Infrastructure (AMI): It permits the two-way interlink between the home and the utility.

3. Automation/in-home display (IHD): It exhibits the user data associated with energy management.

4. Thermostat: It is employed to leverage two-way link, through HAN, to the provider.

5. Smart appliances: The appliances such as fridges, washer, dryers which can respond to distant management process such as pricing, grid integrating and energy management signaling.

6. Home gateway: It has been deployed as an interaction and application link to the provider. It can be placed in the smart meter or used as distinct device and links via internet.

7. Distributed energy resources: It consists of small-scale power production units such as solar, wind, fuel cells, electric vehicles etc.

\section{SMART BUILDINGS}

Revised Manuscript Received on December 15, 2019.

*Correspondence Author

Ms.Nisha.V, Electrical and Electronics Engineering, Kalasalingam Academy of Research and Education, Anand Nagar, Krishnankoil, Virudhunagar, India, nisha.vaasudevan@gmail.com

Dr.V.Vasudevan, Information Technology, Kalasalingam Academy of Research and Education, Anand Nagar, Krishnannkoil, Virudhunagar, India vasudevan_klu@yahoo.co.in

Dr.A.Ramkumar,Electrical and Electronics Engineering, Kalasalingam Academy of Research and Education Anand Nagar, Krishnannkoil, Virudhunagar, India ramkumar.manonmani@gmail.com
Smart buildings are an assimilated and progressive automation system which cover an extensive range of applications such as lighting, temperature, multimedia [14], health monitoring etc. According to the purpose, it can be classified into three types such as Energy smart system, Health smart system and Everyday life handling smart system. Energy smart system deals with the energy supply inside the building comprising both electricity and heat consumption [15]. 


\section{Examination of The Impact of Smart Grid Technologies For Energy Saving Potential on Residential Buildings In India}

Health smart system monitors the health of the people and it can be placed in a private building or a hospital. This system records the patients' health and provides advices on taking medicines. It is possible to create interaction between health and energy smart systems for delivering thermal comfort requirements of the patient [16]. Everyday life handling smart system comprises the data based on methods such as management of available food in the refrigerator or the cupboards by examining the bar code [17].

This study deals energy smart systems alone. Smart energy homes should be the prospect if the energy flux inside a home wants to be organized. In the next decade, the buildings to be constructed will be nearly-zero energy buildings (NZE) and probably a positive energy buildings (PEB). The total energy flow is zero or positive means that building generates energy as the same or more what it consumes. Modeling smart buildings with existing

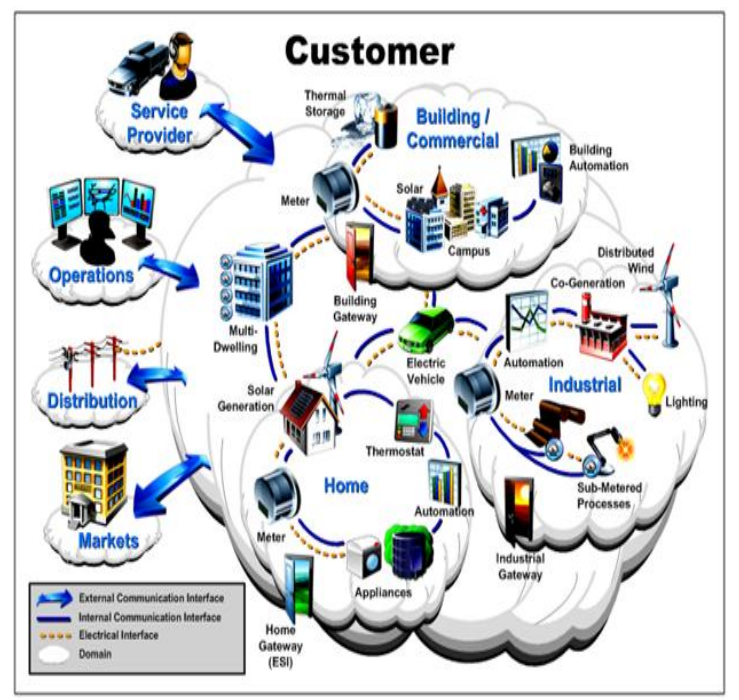

Fig. 1.THEORETICAL MODEL OF THE SMART GRID CUSTOMER DOMAIN

Smart energy home can be implemented in two different methods such as providing information to the consumers regarding energy consumption and through accessing the apparatuses in the home and on and off them distantly. A smart buildings have the following common targets to achieve.

- Gathering real-time information empowering smart mechanization,

- Data management arrangement letting ingestion and generation of energy,

- Data platform,

- Consumer penchants for flexible responses,

- Associate the grid workers facilitating smart grid arrangement,

- Empowering utility and consumer's communication and have a lively energy market,

- Minimizing repairs by employing cloud system,

- Energy pageant in the home, and

Enhancing the billing and payment system

\section{MODELING AN ENERGY EFFICIENT HOME}

Before enabling smart grid to a home, it should be modeled as an energy efficient home. An energy efficient home controls heat flow, air and moisture flow in and out of the building. It interrelates and defines the recital of the home and the health, safety and comfort of the consumers. The modules of an energy efficient home have been

illustrated in Figure 2. A model home with best ventilation process has been shown in Figure 3.

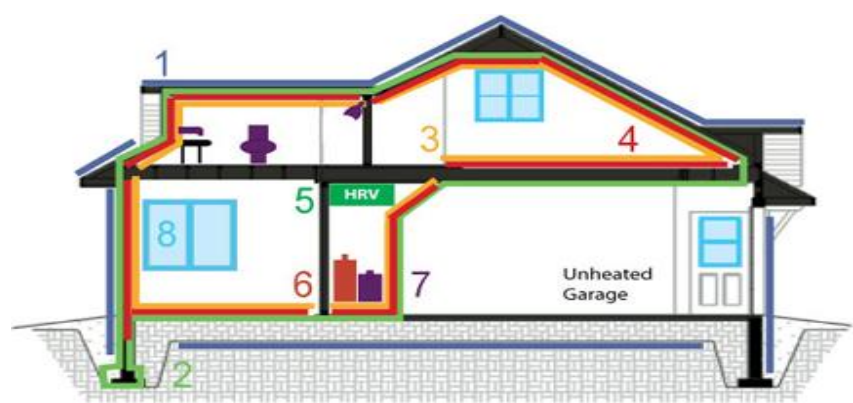

Fig. 2.COMPONENTS OF A TYPICAL ENERGY EFFICIENT HOME

1. External Weather Fence

2. Nonstop Air Fence

3. Internal Moisture Fence

4. Thermal Fence

5. Automatic Airing

6. High Efficacy Heating

7. High Competence Hot Water Tank and Low-Flow Fittings

8. Thermal Window Structure

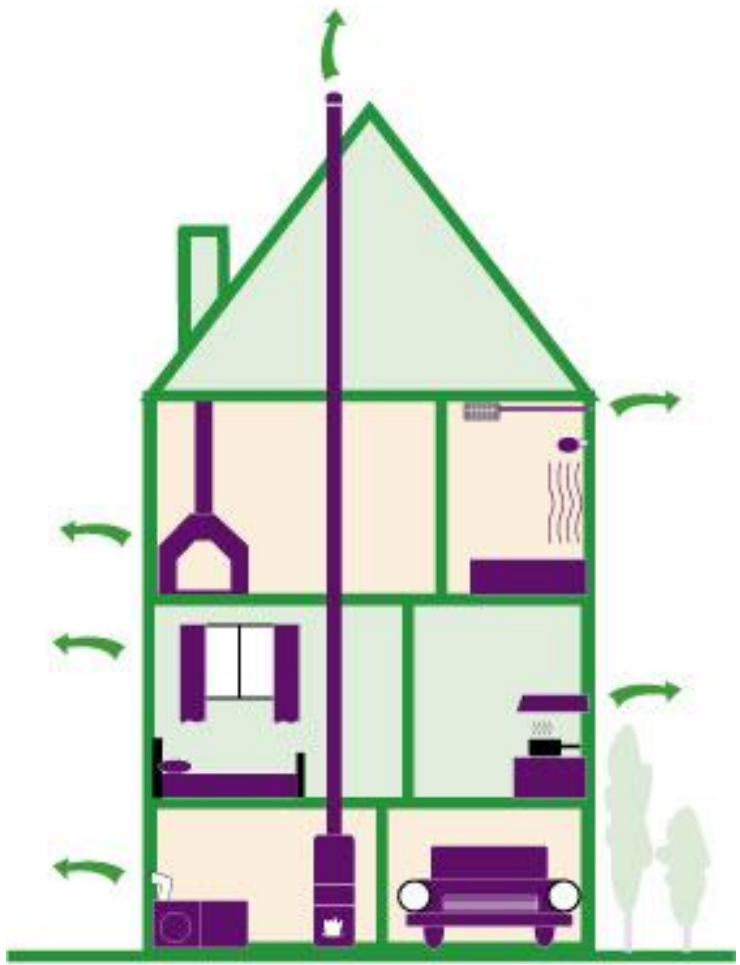

Fig. 3.BEST HOME VENTILATION PRACTICES

The arrows in Figure 3 indicates that the sour, or moisture loaded air being exhausted through hoods, fans, dryer vents and fire place inserts. The guidelines to upgrade a home

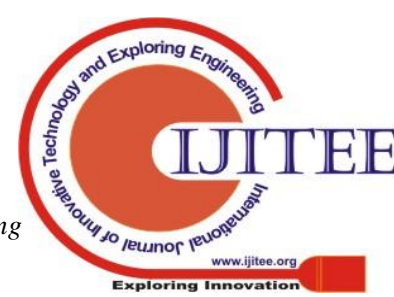


as energy efficient have been listed as follows

- Increase the insulation in loft, walls, basement and crawlspace

- Upgrade heating and cooling systems to a high efficiency model

- Install low flow showerheads and nozzle aerators.

- Make the home as airtight as possible with air sealing and weather stripping while also ensuring proper ventilation systems.

- Try to get incentives from the government for building an energy efficient home.

\section{INTEGRATION OF SMART GRID IN A RESIDENTIAL BUILDING}

This study enables smart grid to a residential building in two ways such as smart systems in existing and upcoming buildings.

\section{A. Smart systems in existing buildings}

Four different cases have been presented to enable smart grid in the existing buildings. The structures of the communication for all the four cases have been shown in Figure 4.

\section{a) Case 1 - The present case}

In this case, all the produced energy should be utilized on site by the consumers. Thus the energy used on site, and the consumption rate has been measured using the smart meter that is connected to the grid. Initially, the grid notifies the utility for estimating the electrical bill. Then, the data can be availed to consumers by the utility. The energy operator handles the data using cloud computing technology. Hence each user can able to survey their consumption rate through internet.

\section{a) Case 2-Energy flux case}

Case 2 is almost similar to case 1 where the distinct presents in the energy flux. A power generation system has been built in the home, it does not utilized by the consumer but can be sold to the utility at a specific price. The smart meter is not availed in consumer side to control the energy flow running in and out but the consumer monitors the energy consumption. The consumers can able to read their energy production through internet that is not linked to the smart meter.

\section{b) Case 3-Improved energy flux case}

In this case, the smart meter can able to analyze the energy cycle from the home to the utility and vice versa. They have the option to return a prompt response of the consumer bill as a notation using a Human-Machine Interface (HMI) as a data acquainting unit.

\section{c) Case 4 - Advanced smart meter case}

An evolution in smart meter can able to examine the energy flux between home and the grid. It can able to regulate the flux of data and energy in this pattern. The advanced smart meters can able to send and receive data with the utility and inform the energy consumption and the energy production of the building. Two types of constructions have been assumed in this case: the first one follows the present pattern. The second one refers "smart plugs" where the accessing of particular

plugs in the devices such as oven, washing machine etc. can be done. It permits the analysis of the electricity consumption for a particular machine and offer the benefit to have a detailed information about the cause for electricity ingestion and electricity outflow in the situation of an excess-consumption of any machines.

\section{B. Smart systems in future buildings}

Smart systems in future buildings will able to control the energy flow to and from the utility. In this system, the smart meters can able to interconnect with each other. The data such as climatic data, energy production, and energy consumption can be exchanged between smart meters. A building would able to see if it is over consuming than other buildings and would able to find out which appliance consumes more. Normally, the smart meter has been employed to monitor the ingestion of each machine and interconnect through the HMI. During overconsumption the consumer can able to control some devices. Figure 5 exhibits the communication structure for enabling smart grids in future buildings.

In future smart building, specific data alone could be salvaged through internet to the utility. Data have been limited inside the smart meter and the current data alone can touch the grid. The remaining data assimilates a closed loop between the building and the smart meter. It infers that the smart meter can able to practice all the data and therefore it assimilates a processor with a panning system to enhance the data dispensation speed, size of the processor and its internal memory. For a four person living energy efficient home, the guidelines for utilizing appliances have been listed in Table 1

TABLE I. GUIDELINES FOR UTILIZING APPLIANCES ECONOMICALLY

\begin{tabular}{|l|l|l|}
\hline \multicolumn{1}{|c|}{ Appliances } & No. of usage per week & Usage time (min) \\
\hline Washing machine & 6.4 & 50 \\
\hline Radio & 20 & 350 \\
\hline Mobile charger & 12 & 400 \\
\hline Heater & 7 & 20 \\
\hline Television & 32 & 98 \\
\hline Cleaner & 2 & 60 \\
\hline Iron & 3 & 70 \\
\hline
\end{tabular}




\section{Examination of The Impact of Smart Grid Technologies For Energy Saving Potential on Residential Buildings In India}

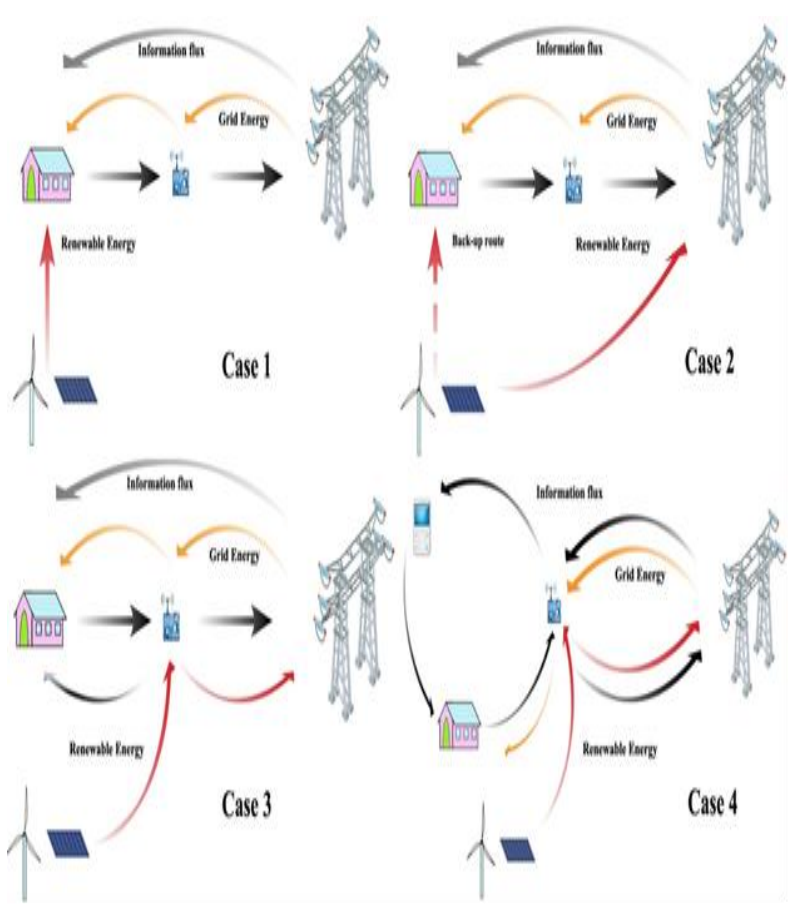

Fig. 4.COMMUNICATION STRUCTURE FOR ENABLING SMART GRIDS IN EXISTING BUILDINGS

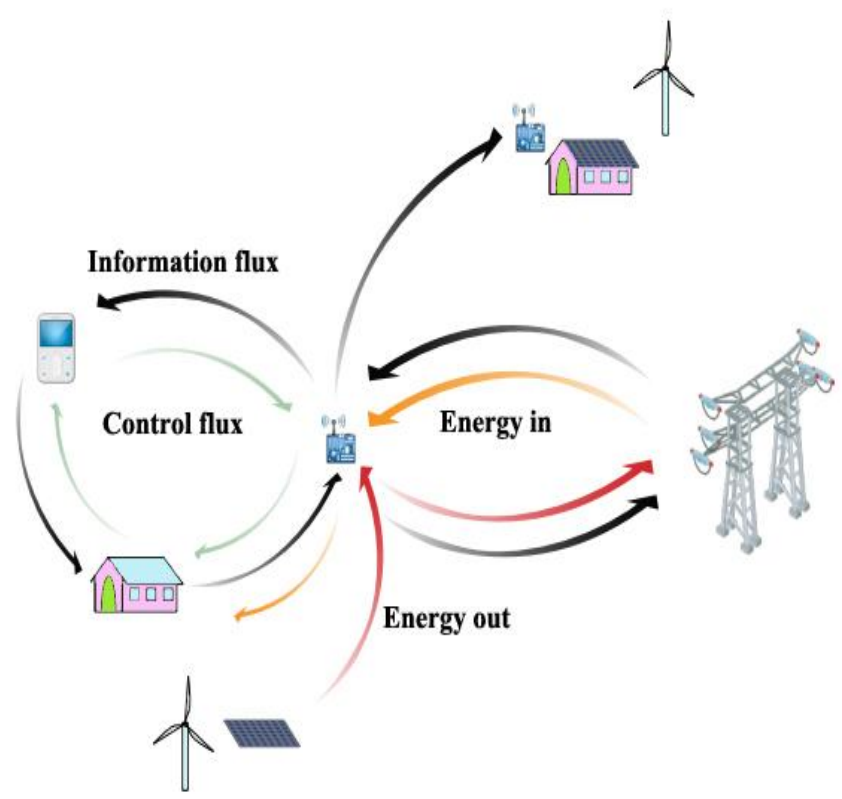

Fig. 5.COMMUNICATION STRUCTURE FOR ENABLING SMART GRIDS IN FUTURE BUILDINGS

TABLE II IMPACTS OF INTEGRATING SMART GRID IN A HOME

\begin{tabular}{|l|l|l|l|l|l|l|l|l|l|l}
\hline Equipment & Lighting & $\begin{array}{c}\text { Space } \\
\text { cooling }\end{array}$ & $\begin{array}{c}\text { Water } \\
\text { heating }\end{array}$ & Fridge & Cooking & Washing & $\begin{array}{c}\text { TV } \\
\text { related }\end{array}$ & $\begin{array}{c}\text { Computer } \\
\text { related }\end{array}$ & Pumps & 0thers \\
\hline $\begin{array}{l}\text { \% of load } \\
\text { share }\end{array}$ & $15 \%$ & $20 \%$ & $9 \%$ & $10 \%$ & $2 \%$ & $1 \%$ & $7 \%$ & $3 \%$ & $8 \%$ & $25 \%$ \\
\hline $\begin{array}{l}\text { Impact of } \\
\text { integrating } \\
\text { smart girid }\end{array}$ & High & Medium & Medium & Medium & Low & Low & High & High & Low & Low \\
\hline
\end{tabular}

\section{CONCLUSION}

An energy profile for a residential building so as to minimize the electricity cost by enabling smart grids have been investigated in this study. Initially, the guidelines have been presented to construct an energy efficient home. The main aim is to design an energy efficient home, and estimate the abilities of smart systems at the building level. Different cases have been proposed to enable that home to the smart grid through a human-machine interface. Smart energy meter has been installed to compute the energy price. Moreover, the procedures have been provided to integrate the smart grid to the future buildings. The impacts of enabling smart grids and energy saving potential have been listed. Numerous researches are in progress worldwide for enhancing energy savings in a home through smart grids by communication engineers, control system engineers as well as architects. Hence, a huge possibility is available in the modeling of smart buildings for energy conservation.

\section{REFERENCES}

1 "India Country Report on Smart Grid," Department of Science and Technology, Government of India, New Delhi2017.

2 S. S. S. R. Depuru, L. Wang, V. Devabhaktuni, and N. Gudi, "Smart meters for power grid - Challenges, issues, advantages and status," in 2011 IEEE/PES Power Systems Conference and Exposition, 2011, pp $1-7$

3 M. Wissner, "The Smart Grid - A saucerful of secrets?," Applied Energy, vol. 88, no. 7, pp. 2509-2518, 2011/07/01/ 2011.

4 D. J. Kang, J. J. Lee, B. H. Kim, and D. Hur, "Proposal strategies of key management for data encryption in SCADA network of electric power systems," International Journal of Electrical Power \& Energy Systems, vol. 33, no. 9, pp. 1521-1526, 2011/11/01/ 2011.

5 E. Corry, P. Pauwels, S. Hu, M. Keane, and J. O'Donnell, "A performance assessment ontology for the environmental and energy management of buildings," Automation in Construction, vol. 57, pp. 249-259, 2015/09/01/ 2015.

6 S. Firth, K. Lomas, A. Wright, and R. Wall, "Identifying trends in the use of domestic appliances from household electricity consumption measurements," Energy and Buildings, vol. 40, no. 5, pp. 926-936, 2008/01/01/ 2008.

7 C. A. Fróes Lima and J. R. Portillo Navas, "Smart metering and systems to support a conscious use of water and electricity," Energy, vol. 45, no. 1, pp. 528-540, 2012/09/01/2012.

8 C. Lath and A. Punchihewa, "Smart home system operating remotely Via $802.11 \mathrm{~b} / \mathrm{g}$ wireless technology," in Fourth International Conference Computational Intelligence and Robotics and Autonomous Systems, 2007.

9 M. Cepeda and M. Saguan, "Assessing long-term effects of demand response policies in wholesale electricity markets," International Journal of Electrical Power \& Energy Systems, vol. 74, pp. 142-152, 2016/01/01/ 2016.

10 P. Faria and Z. Vale, "Demand response in electrical energy supply: An optimal real time pricing approach," Energy, vol. 36, no. 8, pp 5374-5384, 2011/08/01/ 2011. 
11 F. H. Magnago, J. Alemany, and J. Lin, "Impact of demand response resources on unit commitment and dispatch in a day-ahead electricity market," International Journal of Electrical Power \& Energy Systems, vol. 68, pp. 142-149, 2015/06/01/ 2015.

12 C. Aghemo, L. Blaso, and A. Pellegrino, "Building automation and control systems: A case study to evaluate the energy and environmental performances of a lighting control system in offices," Automation in Construction, vol. 43, pp. 10-22, 2014/07/01/ 2014.

13 A. Mousavi and V. Vyatkin, "Energy Efficient Agent Function Block: A semantic agent approach to IEC 61499 function blocks in energy efficient building automation systems," Automation in Construction, vol. 54, pp. 127-142, 2015/06/01/ 2015.

14 D. Markovic, D. Cvetkovic, D. Zivkovic, and R. Popovic, "RETRACTED: Challenges of information and communication technology in energy efficient smart homes," Renewable and Sustainable Energy Reviews, vol. 16, no. 2, pp. 1210-1216, 2012/02/01/ 2012

15 K. Kok et al., "Smart houses for a smart grid," in CIRED 2009 - 20th International Conference and Exhibition on Electricity Distribution Part 1, 2009, pp. 1-4.

16 M. Chan, E. Campo, D. Estève, and J.-Y. Fourniols, "Smart homes Current features and future perspectives," Maturitas, vol. 64, no. 2, pp. 90-97, 2009/10/20/ 2009.

17 M. Friedewald, O. D. Costa, Y. Punie, P. Alahuhta, and S. Heinonen, "Perspectives of ambient intelligence in the home environment," Telematics and Informatics, vol. 22, no. 3, pp. 221-238, 2005/08/01/ 2005 .

\section{AUTHORS PROFILE}

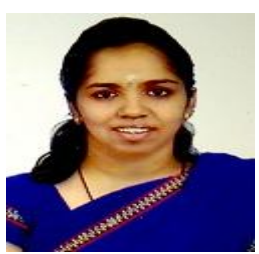

Ms. V. Nisha was born in Chennai, Tamil Nadu, India. She received her UG degree in Electrical and Electronics Engineering from Sathyabama University, Chennai and M.E. degree in Power Electronics and Drives from Anna University, Chennai, Tamil Nadu, India, in 2015. Since September 2015, she has been working as an Assistant Professor in the Department of Electrical \& Electronics Engineering, Kalasalingam University, Krishnankoil, Virudhunagar District, Tamil Nadu and India. She has attended several international conferences and he has been actively involving herself in research since 2017. She has actively participated in various faculty development programs, symposiums, orientation programs, workshops and national seminars.

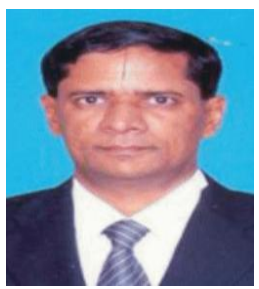

Dr.V. Vasudevan received Ph.D. degree in 1992. $\mathrm{He}$ is currently serving as Registrar and Senior Professor with the school of Computing and information sciences, Kalasalingam University, India. He has published 60 papers in International journals and International conferences. His current research interests include Distributed Computing, Grid Computing, Cloud Computing and Image Processing. He has large volume of publications in refereed journals. He is a life time member of Indian Society of Technical Education (ISTE).

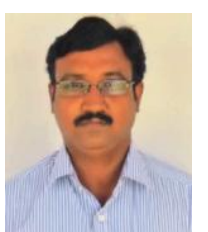

Dr. A. Ramkumar received the Ph.D degree from Kalasalingam Academy of Research andEducation in the year of 2014. He received the M.E (Power Systems) degree from Faculty of Engineering and Technology, Annamalai University, Chidambaram, Tamil Nadu, India, in2002 and received the B.E (Electrical and Electronics Engineering) from Thiagarajar Collegeof Engineering, M.K. University, Madurai, Tamil Nadu, India in the year of 1997. He hasbeen working as a Associate Professor in the Department of Electrical and ElectronicsEngineering, Kalasalingam Academy of Research and Education, Srivilliputhur, Tamil Nadu,since 2003. He is having more than 19 years' experience in the field of teaching. His researchinterests include Renewable Energy, Power System Planning, Power System Analysis, HighVoltage DC transmission Systems, Reactive Power Compensation, Flexible ACtransmissions Systems, Electrical Machines and Power System Automation. He is a Lifemember of ISTE and Member of IE(I). 